\title{
Evaluation of Growth Performance of Tomato in Response to Biochar and Arbuscular Mycorrhizal Fungi (Amf) Inoculation
}

\author{
${ }^{*}$ S. A. Yusif, ${ }^{2}$ M. O. Dare, ${ }^{3}$ S. Haruna, ${ }^{4}$ F. D. Haruna \\ ${ }^{1}$ Department of Soil Science and Agricultural Engineering, Faculty of Agriculture, Usmanu Danfodiyo University, Sokoto, Nigeria. \\ 2Department of Soil Science and Land Management, College of Plant Science and Crop Production, Federal University of \\ Agriculture Abeokuta, Nigeria. \\ 3Department of Forestry, Audu Bako College of Agriculture, Thomas, Dambatta, P.M.B. 3159, Kano State, Nigeria. \\ ${ }^{4}$ Department of Crop Production and Protection, Faculty of Agriculture, Federal University Dutsin-ma, Katsina State, Nigeria.
} [Corresponding author: E-mail: yusifsunusiabdu@gmail.com, yusif.sunusi@udusok.edu.ng P+2348068969633]

\section{ABSTRACT}

Field experiment was conducted in 2013 and 2014 to evaluate growth performance of two tomato genotypes in response to biochar application and arbuscular mycorrhizal fungal (AMF) inoculation at the Teaching and Research Farm, Federal University of Agriculture, Abeokuta. The experiment was laid out in a split-split plot design with two tomato genotypes in the main plots, five levels of biochar application in the sub plots and two levels of AMF inoculation in the sub-sub plots. Data on plant height number of leaves and dry matter yields were generated and subjected to analysis of variance and significant means separated using Duncan's Multiple Range Test at $5 \%$ level of significance. The result shows that mycorrhizal inoculation significantly increased $(p<0.05)$ the shoot dry matter yield $\left(2935.8 \mathrm{~kg} \mathrm{ha}^{-1}\right)$ when compared with non-mycorrhizal plants, there is no significant difference in number of leaves, height and root dry matter yield. Application of $20 \mathrm{t} \mathrm{ha}^{-1}$ of biochar significantly increased $(p<0.05)$ the shoot dry matter yields and plant height while no significant differences were observed in number of leaves and root dry matter yield. From the results obtained it can be concluded that AMF can successfully be inoculated into biochar amended soil to improve the performance of tomato plant.

Keywords: Biochar; AMF; inoculation; tomato; growth performance.

\section{INTRODUCTION}

Tomato (Lycopersicon esculentum Mill.) is one of the most popular and important commercial vegetable crops grown throughout the world. It is a good source of lycopene and acts as anticarcinogen (Kirankumar et al., 2008). Kubota et al. (2005) opined that tomato is recognized as a mycotrophic plant; therefore, the use of arbuscular mycorrhizal fungi (AMF) as biofertilizer has been recommended with the intention to improving production and reducing inorganic fertilizer use. AMF are the most abundant fungi in soil and engage in symbiotic relationships with majority of plants and their direct inoculation of plants have been found to enhance plant growth (Jeffries et al.,2003; Duponnois et al.,2005) and tolerance to different types of biotic and abiotic stresses (Rosendahl and Rosendahl, 1991; Caravaca et al.,2003).

Harvey et al. (1976) reported that application of biochar can have positive effects on abundance and colonization of host plant by AMF and thus promotes plant growth. Nishio (1996) opined that application of biochar stimulates indigenous arbuscular mycorrhizal fungi in soil and thus promotes plant growth. Matsubara et al. (2002) suggested that biochar can also increase the ability of AMF to assist their host plants in resisting infections by plant pathogens. Chan et al. (2008) found that biochar significantly increased total dry matter even at the lowest level of application (10 $\mathrm{t} \mathrm{ha-1}$ ), and the yield increased with increased levels of biochar application to $50 \mathrm{t}$ ha $^{-1}$. However, knowledge of the effect of biochar application and mycorrhizal inoculation on plant growth is scarce as both may adversely affect plant performance (Warnock et al., 2007). The objective of this research is to evaluate the growth performance of two tomato genotypes in response to biochar application and AMF inoculation. 


\section{MATERIALS AND METHODS}

\section{Experimental Site}

The experiment was carried out at the Teaching and Research Farm of the Federal University of Agriculture, Abeokuta, Ogun State, Nigeria, between December, 2013 to May, 2014. The area lies in South Western Nigeria and it is located between Latitude $7^{\circ} 12^{\prime} \mathrm{N}$ and Longitude $3^{\circ} 20^{\prime} \mathrm{E}$. The area is located within a region characterized by a bimodal rainfall pattern (commencing in March; plentiful in July and September, with a short dry spell in August). The long dry season extends from November to March. Annual rainfall ranges between 1400 and $1500 \mathrm{~mm}$ in Abeokuta and environs and daily temperature ranges between $24{ }^{\circ} \mathrm{C}$ and $30^{\circ} \mathrm{C}$. The soil of the area was sandy loam.

\section{Biochar Production and Tomato Nursery}

The maize-cob biochar was produced using gasification method at a temperature of about $300{ }^{\circ} \mathrm{C}$ to $400{ }^{\circ} \mathrm{C}$ (Xu et al., 2012). The biochar was incorporated onto the field two weeks before transplanting at the rates of $0,5,10,15$ and $20 \mathrm{t} \mathrm{ha}^{-1}$. AMF was inoculated to the soil during the nursery planting at the rate of $80 \mathrm{~g}$ per $5 \mathrm{~kg}$ of sterilized top soil and the other nursery buckets left un-inoculated for each of the two tomato genotypes. The tomato genotypes were "Ex-Lafia" and "Ex-Lokoja" which were sourced from local farmers in Lafia and Lokoja, Nassarawa and Kogi States, Nigeria, respectively. The experiment was maintained for 4 weeks after which the tomato seedlings were transplanted to the field.

\section{Experimental Design}

The total plot size was $315 \mathrm{~m}^{2}$ with the sub-sub plot size of $2 \mathrm{~m} \times 1 \mathrm{~m}$, a spacing of $1 \mathrm{~m}$ between and within sub-sub plots. The plant spacing was $30 \mathrm{~cm}$ between and within the plant stands consisting of eighteen plants per sub-sub plot. The field layout was split- split plots design with two tomato genotypes in the main plots, five rates of biochar application in the sub plots and two levels of AMF inoculation (with and without) in the sub-sub plots and replicated three times. Weeding was done manually at 4 and 8 weeks after transplanting (WAT) while cypermethrin (insecticide) was applied at 2, 6, and 9 WAT at the rate of $450 \mathrm{ml}$ of active ingredients per 100 liters of water per hectare of land using knapsack sprayer. The agronomic parameters determined were plant height $(\mathrm{cm})$, number of leaves, shoot dry matter yield $\left(\mathrm{kg} \mathrm{ha}^{-1}\right)$, and root dry matter yield ( $\mathrm{kg}$ ha$1)$. Plant height and number of leaves were carried out at 2, 4, 6, 8, 10 and 12 WAT (FAO, 1980). Shoot and root dry matter yields were obtained by air-drying followed by oven-drying at $60^{\circ} \mathrm{C}$ for 24 hours.

\section{Data Analysis}

The data obtained from this study was subjected to separate analysis of variance (ANOVA) using PROC GLM in SAS to compute mean squares of each of the experimental treatments. Means were separated using Duncan's Multiple Range Test at $5 \%$ level of significance.

\section{RESULTS AND DISCUSSION \\ Biochar Chemical Characteristics}

The results of the biochar composition used in this study are presented in Table 1.

Table 1: Chemical Characteristics of Biochar Used in the Study

\begin{tabular}{lc}
\hline PARAMETERS & BIOCHAR \\
\hline $\mathrm{pH}$ H2O(1:1) & 10.12 \\
$\mathrm{O} \mathrm{C} \%$ & 14.4 \\
$\mathrm{~N} \%$ & 1.94 \\
Total P (mgkg-1) & 31 \\
$\mathrm{~K} \%$ & 2.29 \\
$\mathrm{Mg} \%$ & 0.022 \\
Fe \% & 0.13 \\
\hline Key: OC = Organic carbon, $\mathrm{N}=$ Nitrogen, P $=$ \\
Phosphorous, K = Potassium and Mg = Magnesium, Fe \\
= iron.
\end{tabular}

\section{Plant Heights}

There was no significant difference $(p<0.05)$ in the plant height of tomato between mycorrhizal and non-mycorrhizal plants across the weeks except at 2 WAT when non-mycorrhizal plants 
were significantly $(p<0.05)$ higher than mycorrhizal plants (Table 2). Non-significant effect $(p<0.05)$ of mycorrhizal inoculation towards plant height may be attributed to the incorporation of biochar which has high phosphorus content- a limiting factor in the functions of AMF. This agrees with the results of Abbott and Robson (1991) who reported that mycorrhizal colonization in peanut plants was significantly depressed by adding Phosphorus. Sanchez and Salinas (1981) related the reduction in AM root colonization probably to high soil fertility level, which reduced the dependence of the plants on mycorrhizae and therefore restricted the development of these fungi to the root cortex. Application of biochar at $20 \mathrm{t} \mathrm{ha}^{-1}$ produced significantly higher plants height than control at 4, 6, and 8 WAT except at 2 and 10 WAT while at 12 WAT the least was found with $5 \mathrm{t} \mathrm{ha}^{-1}$ of biochar. However, $20 \mathrm{t}$ ha1 of biochar application rate was found to be comparable with 5,10 and $15 \mathrm{t} \mathrm{ha}^{-1}$ of biochar application rates. Similar result was reported by Khan et al. (2008) who found an increase in plant height due to biochar application and attributed it to positive effect of biochar in supplying essential nutrients for vegetative growth. The genotype Ex-Lokoja had significantly higher height plants than Ex-Lafia genotype across the weeks except at 12 WAT when no significant difference $(p>0.05)$ was observed. Significant interactions $(p<0.05)$ were observed between genotype and AMF and between biochar and AMF (Table 2).

Table 2: Effects of Genotype, Biochar and AMF Inoculation on Heights of Tomato Plants in the Field

\begin{tabular}{|c|c|c|c|c|c|c|}
\hline & & ant height & (cm) & & & \\
\hline & 2 WAT & 4 WAT & 6 WAT & 8 WAT & 10WAT & 12WAT \\
\hline Genotype (G) & & & & & & \\
\hline Ex-Lafia & $8.08^{b}$ & $13.38^{b}$ & $28.08 \mathrm{~b}$ & $55.60^{b}$ & $67.04^{b}$ & $61.45^{a}$ \\
\hline Ex-Lokoja & $10.90^{a}$ & $18.37^{a}$ & $34.95^{a}$ & $68.02^{a}$ & $80.40^{a}$ & $66.03^{a}$ \\
\hline SE \pm & 0.30 & 0.67 & 1.35 & 1.74 & 2.45 & 1.57 \\
\hline Biochar rate $(\mathrm{B})$ & & & & & & \\
\hline 0 & $8.93^{a}$ & $13.41^{b}$ & $27.22^{b}$ & $57.16^{b}$ & $72.39 a$ & $62.91^{\mathrm{ab}}$ \\
\hline 5 & $8.99 a$ & $15.08^{a b}$ & $29.01 \mathrm{ab}$ & $58.52^{a b}$ & $69.68^{a}$ & $56.79 b$ \\
\hline 10 & $10.34^{a}$ & $16.71 \mathrm{ab}$ & $32.37^{a b}$ & $63.62^{a b}$ & $76.08^{a}$ & $65.11^{a}$ \\
\hline 15 & $9.49^{a}$ & $16.71^{\mathrm{ab}}$ & $33.38^{a b}$ & $62.51^{\mathrm{ab}}$ & $75.90^{a}$ & $67.59^{a}$ \\
\hline 20 & $9.72^{a}$ & $17.45^{a}$ & $35.60^{a}$ & $67.21^{a}$ & $74.58^{a}$ & $66.31^{a}$ \\
\hline SE \pm & 0.50 & 1.06 & 2.13 & 2.75 & 3.88 & 2.49 \\
\hline$G^{*} B$ & ns & ns & ns & ns & ns & ns \\
\hline $\operatorname{AMF}(A)$ & & & & & & \\
\hline+ (inoculated) & $9.02^{b}$ & $15.11^{a}$ & $30.26^{a}$ & $62.53^{a}$ & $75.57^{a}$ & $64.88^{a}$ \\
\hline - (uninoculated) & $9.97^{a}$ & $16.63^{a}$ & $32.77^{a}$ & $61.10^{a}$ & $71.87^{a}$ & $62.61^{\mathrm{a}}$ \\
\hline SE \pm & 0.30 & 0.67 & 1.35 & 1.74 & 2.45 & 1.57 \\
\hline$G^{*} A$ & * & ns & ns & ns & ns & ns \\
\hline$B^{*} A$ & ** & ns & ns & ns & ns & ns \\
\hline$G^{*} B^{*} A$ & ns & ns & ns & ns & ns & ns \\
\hline
\end{tabular}

Means within the same column with the same letters are not significantly different according to Duncan's Multiple Range Test at $(p<0.05)$. ns, not significant; ${ }^{*}$, significant at $p<0.05,{ }^{* *}$, highly significant at $p<0.01$, WAT (Weeks after transplanting).

\section{Number of Tomato Leaves Plants}

Mycorrhizal inoculation does not have significant effect on the number of leaves at 2 , 6, 8, 10 and 12 WAT except at 4 WAT, when non mycorrhizal plants had significantly $(p<0.05)$ higher number of leaves compared to mycorrhizal plants (Table 3 ). This is similar to the results reported by Abdullahi and Sheriff (2013) that no significant difference $(p>0.05)$ in number of leaves per plant due to mycorrhizal inoculation at 4 weeks after transplant (WAT) was observed. There was no significant difference $(p>0.05)$ in number of leaves due to biochar rates at $2,8,10$, and 12 WAT. 
However, at 4 WAT the $20 \mathrm{t} \mathrm{ha}^{-1}$ of biochar produced significantly $(p<0.05)$ higher number of leaves when compared with control but comparable with 5,10 , and $15 \mathrm{t} \mathrm{ha}^{-1}$ of biochar rates. The $20 \mathrm{t} \mathrm{ha}^{-1}$ of biochar also produced significantly $(p<0.05)$ higher number of leaves when compared with 0,5 , and $15 \mathrm{t} \mathrm{ha}^{-1}$ but comparable with $10 \mathrm{tha}^{-1}$ of biochar rates at 6 WAT. Similar result was reported by Yusif et al. (2016) who found no significant difference $(p>0.05)$ in number of leaves among biochar rates. Also Chan et al., (2008) observed that at $50 \%$ flower stage, biochar did not influence the number of leaves per plant. Ex-lokoja genotype was observed to produce significantly $(p<0.05)$ higher number of leaves at 2, 6, 8 WAT than Ex-Lafia genotype. Significant interactions in the number of leaves were observed between genotype and biochar at 12 WAT and also among genotype, biochar and AMF at 12 WAT (Table 3).

Table 3: Effects of Genotype, Biochar and AMF Inoculation on Number of Leaves of Tomato Plants in the Field.

\begin{tabular}{|c|c|c|c|c|c|c|}
\hline \multicolumn{7}{|c|}{ Number of leaves } \\
\hline & 2 WAT & 4 WAT & 6 WAT & 8 WAT & 10WAT & 12WAT \\
\hline \multicolumn{7}{|l|}{ Genotype (G) } \\
\hline Ex-Lafia & $3.49^{b}$ & $7.39^{a}$ & $17.26^{b}$ & $32.99 \mathrm{~b}$ & $46.38^{a}$ & $41.74^{a}$ \\
\hline Ex-Lokoja & $3.94^{a}$ & $8.34^{a}$ & $21.31^{a}$ & $43.02^{a}$ & $48.56^{a}$ & $40.08^{a}$ \\
\hline SE \pm & 0.14 & 0.39 & 1.14 & 2.11 & 2.37 & 1.77 \\
\hline \multicolumn{7}{|c|}{ Biochar rate $(\mathrm{B})$ t ha-1 $^{-1}$} \\
\hline 0 & $3.58^{a}$ & $6.56^{b}$ & $17.11^{b}$ & $32.45^{a}$ & $43.14^{a}$ & $39.03^{a}$ \\
\hline 5 & $3.86^{a}$ & $8.03^{a b}$ & $17.43^{b}$ & $36.00^{a}$ & $43.68^{a}$ & $36.96^{a}$ \\
\hline 10 & $3.87^{a}$ & $7.69 \mathrm{ab}$ & $19.20^{a b}$ & $42.33^{a}$ & $51.39 a$ & $40.60^{a}$ \\
\hline 15 & $3.51^{\mathrm{a}}$ & $8.42^{a b}$ & $18.43^{b}$ & $37.80^{a}$ & $51.49 a$ & $43.42^{a}$ \\
\hline 20 & $3.76^{a}$ & $8.63^{a}$ & $24.25^{a}$ & $41.43^{a}$ & $47.67^{a}$ & $44.34^{a}$ \\
\hline SE \pm & 0.22 & 0.62 & 1.79 & 3.33 & 3.75 & 2.79 \\
\hline$G^{*} B$ & ns & ns & ns & ns & ns & * \\
\hline \multicolumn{7}{|l|}{$\operatorname{AMF}(A)$} \\
\hline+ (inoculated) & $3.68^{a}$ & $7.28^{b}$ & $18.04^{a}$ & $37.37^{a}$ & $47.11^{\mathrm{a}}$ & $41.11^{a}$ \\
\hline - (uninoculated) & $3.75^{\mathrm{a}}$ & $8.46^{\mathrm{a}}$ & $20.52^{a}$ & $38.64^{a}$ & $47.83^{a}$ & $40.71^{a}$ \\
\hline SE \pm & 0.14 & 0.39 & 1.14 & 2.11 & 2.37 & 1.77 \\
\hline $\mathrm{G}^{*} \mathrm{~A}$ & ns & ns & ns & ns & ns & ns \\
\hline$B^{*} A$ & ns & ns & ns & ns & ns & ns \\
\hline$G^{*} B^{*} A$ & ns & ns & ns & ns & ns & ** \\
\hline
\end{tabular}

\section{Shoot and Root Dry Matter Yields}

Mycorrhizal plants had significantly $(p<0.05)$ higher shoot dry matter yields compared to non-mycorrhizal plants (Table 4). This could be attributed due to the ability of mycorrhizae to improve absorption of nutrients. The result agrees with the findings of previous researchers including Al-Karaki et al. (1998) who reported increase shoot dry matter yields with mycorrhizal inoculation in wheat plants (Triticum aestivum L.). However, no significant difference $(p<0.05)$ was observed in root dry matter yields due to mycorrhizal inoculation. Similar result was found by Ebrahim and Nasser (2013) that mycorrhizal treatments had no significant effect $(p<0.05)$ on root dry matter yield of tomato plants. Shoot dry matter yields increased with increasing rate of biochar application with $20 \mathrm{t} \mathrm{ha}^{-1}$ of biochar producing significantly $(p<0.05)$ higher shoot dry matter yields. However, $20 \mathrm{t}^{\mathrm{a}} \mathrm{a}^{-1}$ of biochar application rate was found to be comparable with 10 and $15 \mathrm{t} \mathrm{ha}^{-1}$ of biochar application rates in shoot dry matter yields. Increase in shoot dry matter 
yield due to addition of biochar was reported by Warnock (2004) and Chan et al. (2008) who found that biochar significantly increased $(p<0.05)$ shoot dry matter yield even at the lowest level of application. No significant difference $(p<0.05)$ was observed in root dry matter yields among biochar rates. A study conducted by Yusif et al. (2016) reported no significant difference in root dry matter yield among biochar rates. Ex-Lokoja genotype produced significantly higher $(p<0.05)$ shoot dry matter yield than Ex-Lafia genotype. Significant interactions $(p<0.05)$ were observed between genotype and biochar in shoot dry matter yields.

Table 4: Effect of Genotype, Biochar and AMF Inoculation on Dry Matter Yields in the Field

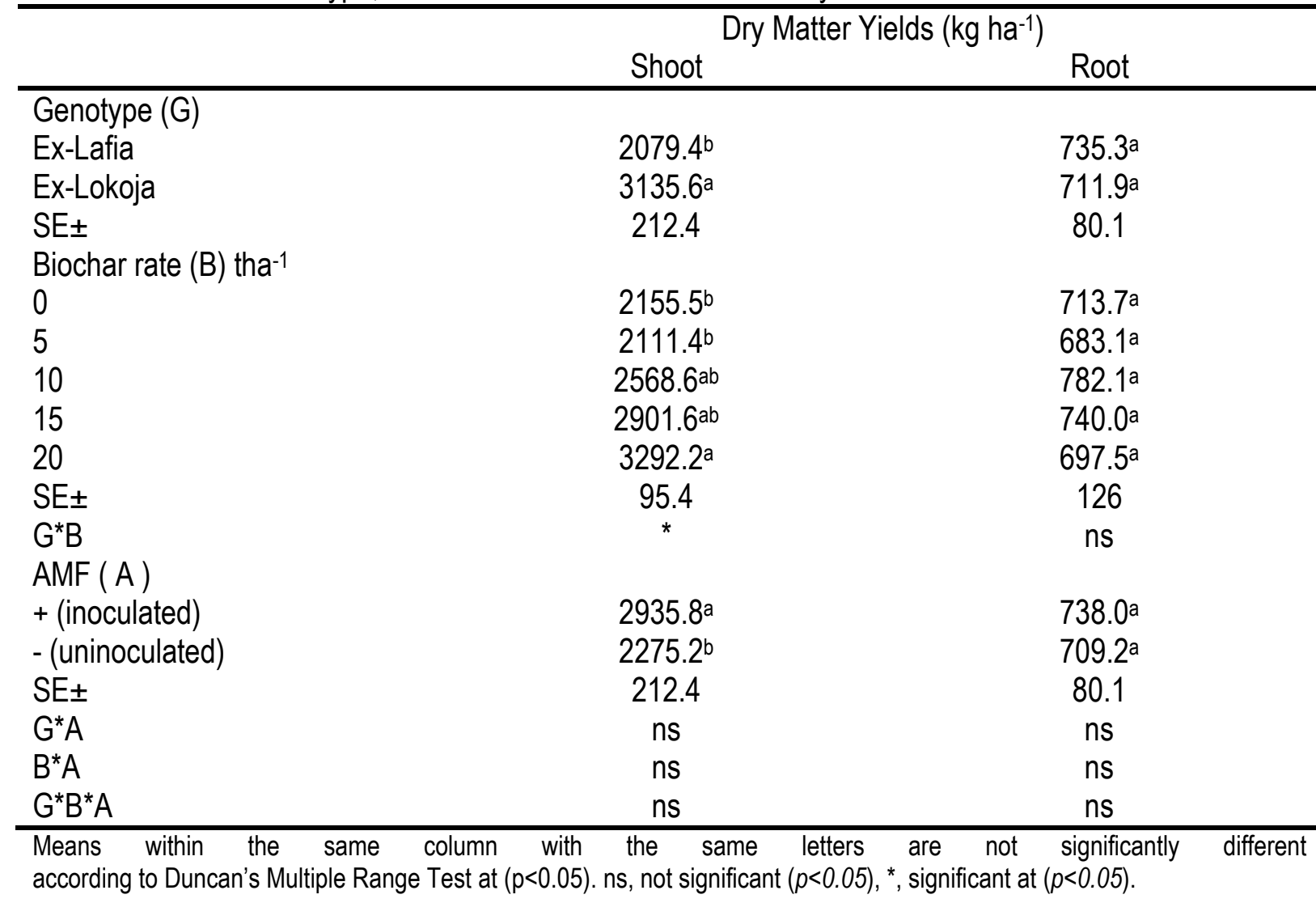

\section{CONCLUSION}

The higher nutrient content of the biochar was identified as the main factor increasing shoot dry matter yield and plant height. AMF inoculation improved shoot dry matter yield. Therefore, AMF can successfully be inoculated in biochar amended soil for improved performance of tomato in the study area. Biochar rate of $20 \mathrm{t} \mathrm{ha}^{-1}$ could be used for enhancement of plant performance. Ex-Lokoja genotype generally performed better than ExLafia genotype in almost all the growth parameters examined.

\section{REFERENCES}

Abdullahi, R. and Sheriff, H.H (2013). Effect of arbuscular mycorrhizal fungi and chemical fertilizer on growth and shoot nutrients content of onion under field condition in Northern Sudan Savanna of Nigeria. IOSRJournal of Agriculture and Veterinary Science, 3(5): 85-90.

Abbott, L.K. and Robson, A.D (1991). Field management of VA mycorrhizal fungi. In: D.L. Keister and P.B. Cregan (eds) The Rhizosphere and Plant Growth, Kluwer Academic Publishers, Dordrecht, pp. 355362.

Al-Karaki, G.N., Al-Raddad A. and Clark, R.B (1998). Water stress and mycorrhizal soybean from sewage-sludge-treated soil. Soil Science Society of America Journal, 55: 393-398.

Caravaca, F., Barea, J.M., Palenzuela, J., Figueroa, D., Alguacil, M.M. and Roldán, A (2003). Establishment of shrub species in a 
degraded semiarid site after inoculation with native orallochthonous arbuscular mycorrhizal fungi. Applied Soil Ecology, 22(2): 103- 111.

Chan, K.Y., Van Zwieten, L., Meszaros, I., Downie, A. and Joseph, S (2008). Using poultry litter biochars as soil amendments. Australian Journal of Soil Research, 46:437 - 444.

Duponnois, R., Colombet, A., Hien, V. and Thioulouse, J (2005). The mycorrhizal fungus Glomus intraradices and rock phosphate amendment influence plant growth and microbial activity in the rhizosphere of Acacia holosericea. Soil Biology and Biochemistry, 37: 1460-1468.

Ebrahim, S. and Nasser, A (2013). Influence of Glomus etunicatum and Glomus intraradices fungi of inoculums and micronutrient deficiency on root colonization and dry weights of tomato and sorghum in perlite bed culture. African Journal of Biotechnology, 12(25): 39573962.

FAO (1980). Soil and plant testing as a basis of fertilizer recommendations. Soil Bulletin 3812.

Harvey, A.E., Jurgensen, M. F. and Larsen, M. J (1976). Comparative distribution of ectomycorrhizae in a mature Douglasfir/Larch forest soil in western Montana. Forest Science, 22: 350-358.

Jeffries, P., Gianinazzi, S., Perotto, S., Turnau, K. and Barea, J.M (2003). The contribution of arbuscular mycorrhizal fungi in sustainable maintenance of plant health and soil fertility. Biology and Fertility of Soils, 37: 116.

Khan, H.Z., Malik, M.A. and Saleem, M.F (2008). Effect of rate and source of organic material on the production potential of spring maize (Zea mays L.). Pakistan Journal of Agricultural Science, 45(1): 4043.

Kirankumar, R., Jagadeesh, K.S., Krishnaraj, P.U. and Patil, M.S (2008). Enhanced growth promotion of tomato and nutrient uptake by plant growth promoting rhizobacterial isolates in presence of tobacco mosaic virus pathogen. Karnataka Journal of Agricultural Science, 21 (2): 309-311.

Kubota, M., Mcgonigle, T.P, and Hyakumachi, M (2005). Co-occurrence of Arumand Paristype morphologies of arbuscular mycorrhizae in cucumber and tomato. Mycorrhiza, 15: 73-77

Matsubara, Y., Hasegawa, N. and Fukui, H (2002). Incidence of Fusarium root rot in asparagus seedlings infected with arbuscular mycorrhizal fungus as affected by several soil amendments. Journal of the Japanese Society for Horticultural Science, 71:370-374.

Nishio, M (1996). Microbial fertilizers in Japan. FFTC- extension bulletin 1-12. National Institute of Agro-Environmental Sciences, Ibaraki, Japan.

Rosendahl, C.N. and Rosendahl, S (1991). Influence of vesicular arbuscular mycorrhizal fungi (Glomus spp.) on the response of cucumber (Cucumis sativus L.) to salt stress. Environmental and Experimental Botany, 31: 313-318.

Sanchez, P.A. and Salinas, J.G (1981). Low input technology for managing Oxisols and Ultisols in tropical America. Advances in Agronomy, 34: 279-406.

Warnock, D.G (2004). Arbuscular mycorrhizal responses to biochars in soils-potential mechanisms of interactions and observed responses in controlled environments. Master's thesis University of Montana Misssoula, MT.

Warnock, D.D., Lehmann, J., Kuyper, T.W. and Rillig, M.C (2007). Mycorrhizal responses to biochar in soil - concepts and mechanisms. Plant and Soil, 300:9-20

Xu, Z.R., Zhu, W. and Htar, S.H (2012). Partial oxidative gasification of municipal sludge in subcritical and supercritical water. Environment Technology, 33 (10-12): 1217-1223.

Yusif, S.A., Muhammad, I. Hayatu, N.G. Sauwa, M.M Tafinta, I.Y. Mohammed, M.A. Lukman, S.A. Abubakar G.A. and Hussain, A.M (2016). Effects of Biochar and Rhizobium Inoculation on Nodulation and Growth of Groundnut in Sokoto State, Nigeria. Journal of Applied Life Sciences International, 9(2): 1-9. 